\title{
Editorial
}

\section{El Tratado de Libre Comercio (TLC) y sus implicaciones}

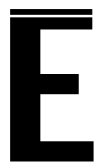

I 12 deoctubre de2011 fueaprobado por el Congreso norteamericano el TLC con los Estados Unidos, y el 21 del mismo mes fuesancionado por el presidenteO bama. Se espera que entre en vigencia cuando los dos países certifiquen que sus nor mas se ajustan al contenido del acuerdo, proceso que demorará, aproximadamente, enitúe ninueve meses y un año. La aprobación del mencionado tratado se convirtió tal vez, en el hecho económico, más importante del año, en la medida en que desde su firma en 2006, hubo una serie de impases que llevó a pensar a algunos analistas que dada la polarización política en Washington, la ratificación final del acuerdo no sería posible sino hasta el próximo año.

Sin duda, como todos los acuerdos comer ciales, estetiene simpatizantes y detractores. Para los primeros, el TLC contribuiráal crecimiento económico, a la generación deempleo y a aumentar las exportaciones. Sobre las bondades de la iniciativa, el presidente Santos manifestó que el tratado contribuirá al crecimiento económico, como mínimo en $1 \%$ más, a generar 250.000 nuevos puestos de trabajo y a incrementar las exportaciones en un $6 \%$, en especial las no tradicionales, tales como las de confecciones, azúcar, ver duras y hor talizas.

También se afirma que debido a queel $90 \%$ de los productos que Colombia lecompra a EEUU son manufacturados, sobre todo bienes de capital y bienes intermedios relacionados con el sector automotriz, el sector minero o el dehidrocarbur os, el sector aéreo, la informática, entre otros -queel país necesita y no produce-, loscuales entrarán a precios más bajos seestimulará la actividad económica de las pequeñas y medianas empresas (PYM ES), ya quela reducción de arancelesdisminuirá suscostos de producción, facilitará la actualización tecnológica y permitirá mayores niveles deproductividad.

Deigual manera, algunas actividades agropecuarias y de producción de alimentos el aborados se verán ben eficiadas, en la medida en que bajarán los precios del trigo, del maíz y de la soya, ya que estos granos son la materia prima para desarrollar dichas actividades.

De otra parte, quienes se oponen a la iniciativa argumentan que varios renglones del sector agropecuario se verán afectados, así como también la industria textil. Sobrelas implicaciones en la agricultura, el propio ministro, Juan Camilo Restrepo, sostuvo: "no estamos preparados". 
De hecho, los sector es arrocer o, lácteo y avícola están en condiciones vulnerables, debido a que es imposible competir con los cuantiosos subsidios quereciben los productor es estadounidenses.

Se afirma que Colombia con el TLC entra a competir con la economía másfuer te del mundo en condiciones desventajosas, ya que EE UU dispone de una base tecnológica y de métodos productivos con los que nuestr o país no cuenta; y de allí su potencial exportador de productos agrícolas, industrialesy deservicios. En el tratado se prevéun proceso acelerado de desgravación arancelaria, que, en muy corto tiempo, afectará no solo a la producción agrícola, sino a los pequeños y medianos industriales, quienes en pocos años estarán expuestos a la libre competencia.

Para los opositor es, el TLC significa la profundización de la apertura unilateral. Argumentan que el mercado estadounidense, si bien es amplio, siempre ha estado abierto, dado que los aranceles en los últimos años han sido relativamente bajos y que el sistema de preferencias arancelarias (APTDEA) los eliminó para casi todos los productos colombianos. De allí que los beneficios que se obtengan con el TLC no sean significativos, en el sentido de elevar sustancialmente las ventas colombianas a EE UU, más bien, lo que puede suceder es que las importaciones crezcan considerablemente, afectando tanto la balanza comercial, como los ingresosfiscales.

El TLC no esla panacea. Es posibleque el potencial productivo quetiene Colombia en algunos rubrosy la posibilidad de incrementar las ventas a EE UU no se materialice, ya queel cuello de botella para lograrlo es, sin duda, la infraestructura vial y de transporte que tiene el país, la cual se caracteriza por ser insuficientee inadecuada. En Colombia, el trasporte demer cancías desde los puertos hacia el interior del país y viceversa, se realiza básicamente por medio del transporte de carga aéreo y por carretera. En las otras modalidades, (tren y barco), su operatividad es casi nula. En cuanto al transporte de carga por carretera, las vías están en condiciones precarias y la amplitud de las mismas no es la más adecuada. De otro lado, la infraestructura aér ea no es la más conveniente. El aeropuerto El Dorado es el tercer puerto aéreo en el tráfico de mercancías en latinoamérica y todavía está en construcción, con el agravante que no se ha decidido si se construye una tercera pista; los demás aer opuer tos, si bien movilizan parte de la carga, representan una reducida proporción.

Luis E. Vallejo Zamudio

Director - Editor 